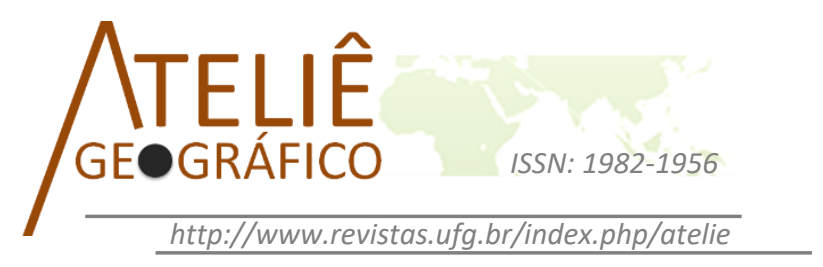

\title{
O ensino do lugar: reflexões sobre o conceito de lugar na Geografia
}

\author{
The teaching of place: reflections on the concept of place in \\ Geography
La enseñanza del lugar: reflexiones acerca del concepto de lugar en la Geografía

Mariângela Oliveira de Azevedo

Rede Municipal de Educação de Goiânia

mariangela.azevedo@hotmail.com

\author{
Elson Rodrigues Olanda \\ PPGEEB/CEPAE/UFG \\ elson.olanda@gmail.com
}

\begin{abstract}
Resumo
O presente trabalho origina-se da dissertação de mestrado intitulada $\mathrm{O}$ ensino do lugar e o lugar do ensino: o conceito de lugar geográfico como dimensão de uma educação emancipadora no Ciclo II do Ensino Fundamental. O artigo que aqui propomos, intitulado "O ensino do lugar: reflexões sobre o conceito de lugar na Geografia", tem por base o capítulo 2 da referida dissertação. Neste trabalho, buscamos realizar uma reflexão específica a respeito do conceito de lugar em Geografia, apresentando diferentes concepções teóricas, especialmente nas linhas crítica e humanística, suas significações científicas e aplicações cotidianas ao ensino de Geografia no Ciclo II do Ensino Fundamental. Ainda, abordamos a relação dialética entre o lugar e o mundo em uma perspectiva multiescalar, imersa no processo de globalização econômica atual. Com isso, intentamos delinear as discussões sobre o lugar geográfico na Geografia acadêmica e na Geografia escolar, identificando e analisando as bases teóricas que nos ancoraram na reflexão sobre a prática pedagógica em sala de aula.
\end{abstract}

Palavras-chave: Ensino de Geografia. Lugar. Ciclo II.

\footnotetext{
Abstract

This paper originates from Chapter 2 of the masters dissertation entitled $O$ Ensino do Lugar e o Lugar do Ensino: o conceito de lugar geográfico como dimensão de uma
} 
educação emancipadora no Ciclo II do Ensino Fundamental ["The Teaching of Place and the Place of Teaching: The Concept of Geographic Place as Part of an Emancipatory Education in Cycle 2 of Brazil's Elementary School']. It presents an indepth analysis of the concept of place in geography, including various theoretical perspectives (particularly the critical and humanistic approaches) and the concept's scientific meanings and daily applications in Geography teaching in Cycle 2 of Brazil's elementary school. Furthermore, this paper addresses the dialectic relation between place and world from a multiscale approach, immersed in present-day economic globalization. Its aim is to shed light on debates concerning the geographic place in both academic and school-based geography, hence identifying and analysing the theoretical foundations required to foster reflections on pedagogical classroom practices.

Keywords: Geography teaching. Place. Cycle 2.

\begin{abstract}
Resumen
Este trabajo se origina de la tesis de maestría titulada La enseñanza del Lugar y el Lugar de la Enseñanza: el concepto de lugar geográfico como dimensión de una educación emancipadora en el Ciclo II de la Enseñanza Básica. El artículo que proponemos, La enseñanza del lugar: reflexiones acerca del concepto de lugar en la Geografía, se fundamenta en el capítulo II de dicha tesis. En el trabajo, buscamos realizar una reflexión específica del concepto de lugar en Geografía, presentando distintas concepciones teóricas, en especial en las líneas crítica y humanística, sus significaciones científicas y aplicaciones cotidianas en la enseñanza de Geografía en el Ciclo II de la Enseñanza Básica, correspondiente a $\operatorname{los} 4^{\circ}, 5^{\circ}$ y $6^{\circ}$ grados; y enfocamos la relación dialéctica entre el lugar y el mundo en una perspectiva multiescalar, inmersa en el proceso de globalización económica actual. Con ello, intentamos delinear las discusiones sobre el lugar geográfico en la Geografía académica y en Geografía escolar, identificando y analizando las bases teóricas que nos sostuvieron en la reflexión sobre la práctica pedagógica en el aula.
\end{abstract}

Palabras clave: Enseñanza de Geografía. Lugar. Ciclo II.

\title{
Introdução
}

O presente trabalho aborda o conceito de lugar e sua importância para o ensino de Geografia no Ensino Fundamental, especialmente no Ciclo II (equivalente ao $4^{\circ}, 5^{\circ} \mathrm{e}$ $6^{\circ}$ anos) dessa etapa da educação básica, considerando as escalas de abordagem em Geografia, que explicam ser o lugar um conceito de abrangência multiescalar.

$\mathrm{O}$ artigo está organizado em três partes, além desta introdução. A primeira, "Conceitos: a construção de pensamentos geográficos escolares", distingue brevemente o ensino escolar por conteúdos e por conceitos, enfatizando a relevância da construção de um pensamento conceitual no processo de aprendizagem escolar. Nela apresentamos uma reflexão geral a respeito do conceito de lugar. No tópico "O lugar na Geografia escolar", tratamos da relevância do conceito de lugar para a Geografia no Ensino Básico. Por último, nas "Considerações finais", sintetizamos a importante relação entre as reflexões teóricas de lugar e a abordagem pedagógica desse conceito. 


\section{Conceitos: construção de pensamentos geográficos escolares}

A prática em sala de aula no ensino de Geografia nos mostra que os estudantes muitas vezes apresentam uma visão de Geografia distante, que não se relaciona com a realidade vivenciada por eles.

Podemos supor que a ideia que os alunos fazem da Geografia, sem vinculá-la a suas próprias vidas, se relacione ao modo como o ensino dessa disciplina desenvolveu-se, historicamente, no universo escolar. Mesmo atualmente, em que se observa certo avanço didático e a ampliação das discussões sobre um ensino crítico, é comum que as práticas pedagógicas sejam de memorização, vinculadas ao livro didático, sem ampliação reflexiva das temáticas e da relação com a realidade. Esse modelo tradicional de ensino, chamado de empirista por Cavalcanti (2013, p. 52), trata de:

[...] ensinar os objetos, os fatos, os acontecimentos, com o objetivo único (ou principal) do ensino de Geografia, como se fossem dados a serem constatados, memorizados, descritos, em si mesmos, como se fossem "coisas" que tivessem sentido e significado neles mesmos.

Essa postura pedagógica frente ao conhecimento geográfico objetiva o aprendizado pelo aprendizado, para fins de avaliação formal, provas de memorização pura que não incentivam a construção de pensamento sobre o mundo em seu sentido espacial. Nessa perspectiva, não se pode falar de formação de conceitos, compreensão e reflexão, mas sim em definições, em reprodução alienada, conteudista e acrítica, que reflete nas visões de mundo e de seres humanos.

Cavalcanti (2010a), ao direcionar a discussão da formação de conceitos para o ensino escolar, chama de escolares aqueles que se formam na articulação entre o conhecimento científico e os conhecimentos cotidianos dos alunos, sendo os primeiros produzidos pela ciência geográfica. A autora salienta a necessidade de que a mediação pedagógica em sala de aula, a partir dos princípios sociointeracionistas de Vygotsky, possibilite aos alunos a construção de conceitos geográficos que aproximem conceitos cotidianos e científicos, não desprezando a importância de ambos.

Alguns conteúdos tratados no ensino de Geografia no Ciclo II do Ensino Fundamental, como o bairro, a cidade, o Planeta Terra e muitos outros, fazem parte de conhecimentos que os alunos já têm de sua vivência, de sua experiência e de suas relações socioculturais. Segundo Moreira (1994, p. 56), "não precisamos frequentar a escola para comungar com a Geografia. Nós a percebemos e a aprendemos por força do nosso próprio cotidiano". Mesmo antes de frequentar a escola, as crianças vivenciam seus espaços - da casa, das ruas, dos lugares de passeio, casa de parentes, amigos, tem acesso às informações fornecidas pelas diversas mídias que se relacionam ao conhecimento geográfico e tantas outras situações do cotidiano carregadas de geografia. Recai em erro o ensino escolar que desconsidera essa experiência como parte da construção do aprendizado científico. 
Propiciar a formação de conceitos reais no ensino de Geografia passa pela construção de conceitos geográficos que ultrapassem o distanciamento promovido pelo ensino tradicional, centrado na memorização e na descrição. Torna-se necessário aproximar o conhecimento geográfico da vida dos alunos, do que eles conhecem efetivamente, do espaço de que fazem parte, e utilizar isso para avançar na compreensão de mundo.

\section{Conceito de lugar: aproximações teóricas}

No senso comum, utilizamos a expressão lugar de forma despretensiosa, para nos referirmos a uma localidade para onde se vai ou se foi. A expressão é também usada como um tipo de referência necessária em ocasiões diversas, sem que se pense muito a respeito de suas implicações. A necessidade de localização, segundo Douglas Santos (2007), originou expressões como "desorientados" (sem Oriente) e "desnorteados" (sem Norte), em geral utilizadas quando as pessoas estão inseguras diante de determinada situação, sem saber como agir ou o que fazer ante o desconhecido. São expressões que refletem a busca humana pelo familiar, pela identidade, pelo reconhecível, pelas formas do espaço geográfico e pelos acontecimentos ou relações sociais. É por isso que, de acordo com o autor, a humanidade busca a construção de sua Geografia, desde a Antiguidade, na identificação de seus lugares: lugar onde a caça é boa, lugar em que se conseguem bons frutos, lugar de proteção e sobrevivência, etc.

Nas experiências socioespaciais, por meio das vivências de cada lugar, as construções geográficas vão se configurando como memória que se constrói coletivamente, dando expressão aos lugares. Historicamente, a necessidade de marcar os lugares e deixar sinais que permitissem ao ser humano voltar, bem como estabelecer relação entre o lugar e a experiência vivida ali e traçar caminhos para diferentes lugares dá origem à necessidade de elaborar mapas e outras representações cartográficas. O lugar, portanto, relaciona-se à própria configuração histórica da Geografia como prática social, como necessidade humana. "O aprendizado relacionado ao reconhecimento dos lugares e de seus significados em nossas vidas se inicia muito antes de entrarmos na escola e depende diretamente das relações sociais nas quais estamos inseridos" (SANTOS, 2007, p. 5).

Os lugares estão relacionados às ideias de identidade, ainda que em graus diferentes. Por exemplo, nossa casa é um lugar carregado de significados de pertencimento singular, ao passo que o planeta Terra é um lugar com sentido de pertencimento, porém ampliado não só em sentido escalar, como também nas experiências vividas.

O lugar não é um ponto definido por coordenadas geográficas, um ponto no espaço, uma localização física ou uma representação cartográfica; ele é a articulação da espacialidade com as relações sociais estabelecidas entre seres humanos e os elementos que compõem esse espaço. 
Na ciência geográfica, durante muito tempo o lugar foi analisado na perspectiva de local, região e espacialidade, ideia especialmente representada na teoria do geógrafo francês Vidal de La Blache, designando uma simples referência de localização em sentido escalar, sem muita intencionalidade do que está implicado no lugar. Entretanto, com as especificidades e a complexidade do mundo atual, os lugares não mais se limitam a essa análise, mas convivem dialeticamente com realidades do mundo que se materializam nos lugares devido à globalização da economia.

Ao buscar elaborações que tratassem da temática, percebemos que as principais linhas de análise do conceito de lugar na Geografia estão presentes na perspectiva humanista e na Geografia crítica. Consideramos as discussões presentes em ambas não desprezando aspectos que, a nosso ver, mesmo antagônicos em determinados pontos, contribuem, com suas especificidades, para a prática educativa.

Tratamos, a seguir, da revisão de literatura do conceito de lugar, categorizandoa em o lugar na ciência geográfica e o lugar na Geografia escolar.

\section{O lugar na ciência geográfica}

O conceito lugar é discutido na ciência geográfica, especialmente pelas perspectivas crítica e humanística. Optamos por não subdividir essas linhas de análise no tópico, pois nossa intenção principal não é a de confrontá-las, apontando diferenças/similaridades teóricas, mas a de apresentar as principais reflexões que possam contribuir para pensar o ensino de Geografia.

Milton Santos (1997), em sua obra A natureza do espaço: técnica e tempo razão e emoção, traz importantes contribuições para pensar o objeto da Geografia, o espaço geográfico, em um contexto de globalização e do modo estruturante da sociedade capitalista. Para o autor, o espaço geográfico configura-se como um conjunto de fixos e fluxos, sendo os fixos o que é próprio do lugar, seu ambiente, por assim dizer, aquilo que é natural ou humanizado no espaço. Os fluxos, por sua vez, podem recriar os fixos, modificando-os e redefinindo os lugares.

Outro ponto de análise de Santos (1997), ao pensar o espaço, é o da configuração territorial relativa às relações sociais. Nesse caso, a configuração territorial aparece como sinônimo de materialidade e o espaço como sendo a reunião da materialidade e da vida (relações sociais). $\mathrm{O}$ autor preocupa-se em expor para o leitor a configuração territorial que, no decorrer do tempo histórico, cada vez mais muda de aspecto, sendo a natureza (o que é natural) substituída por territorialidades humanizadas (ruas, casas, plantações etc.).

Sobre o que seria a Geografia, Santos (1997, p. 51) elabora a seguinte afirmação: "disciplina que cabe estudar o conjunto indissociável de sistemas de objetos e sistemas de ações que formam o espaço". E o espaço é definido como "um conjunto indissociável, solidário e também contraditório de sistemas de objetos e sistemas de ações, não considerados isoladamente, mas num quadro único no qual a história se dá”. Em respeito 
ao sistema de objetos e ações, o autor refere-se ao primeiro como forças produtivas e ao segundo como relações sociais.

A partir do exposto, poderíamos dizer que, na análise de Santos (1997), a Geografia é uma ciência que estuda a sociedade em sua espacialidade, considerando os objetos (forças produtivas) e as ações (relações sociais) como composição do espaço geográfico de maneira contraditória. A partir dessas reflexões, o autor nos propicia chegar ao conceito de lugar: "[a] partir do reconhecimento dos objetos nas paisagens e no espaço, somos alertados para as relações que existem entre os lugares" (SANTOS, 1997, p. 58). É considerando o reconhecimento do espaço geográfico em sua materialidade e nas suas relações sociais que podemos compreender as conexões existentes nos lugares que formam a totalidade-mundo.

Para Santos (1997, p. 46), os lugares não são meras localizações escalares e pontuais, mas reflexos das complexidades sociais que se fazem no tempo histórico e se mostram no espaço: "[a] cada lugar geográfico concreto corresponde, em cada momento, um conjunto de técnicas e de instrumentos de trabalho, resultado de uma combinação específica que também é historicamente determinada".

Outra análise fundamental do autor é sua referência geográfica ao contexto da globalização. Para Santos (1997), uma análise geográfica na perspectiva totalidade-mundo só é possível em relação aos lugares, em uma correlação universal - particular - particular - universal. Sobre o que seria a totalidade, Santos (1997, p. 93) esclarece: “[...] todas as coisas presentes no universo formam uma unidade. Cada coisa nada mais é que parte da unidade, do todo, mas a totalidade não é uma simples soma das partes. As partes que formam a totalidade não bastam para explicá-la. Ao contrário, é a totalidade que explica as partes".

Santos (1997) relaciona a diversidade de aspectos componentes da espacialidade geográfica aos lugares. Um desses aspectos fundantes da sociedade é o trabalho. $\mathrm{O}$ autor considera que, atualmente, a informação se tornou o motor da divisão do trabalho, divisão esta que se materializa nos lugares.

Em sua análise, Santos (1997) apresenta dois níveis relevantes geograficamente: o do mundo e o do lugar. Os eventos, os acontecimentos, especialmente agora, com a globalização, concretizam nos lugares as possibilidades de ação que retiram do mundo, integrando o que é universal e o que é do indivíduo. "O nível global e local do acontecer são conjuntamente essenciais ao entendimento do mundo e do lugar" (SANTOS, 1997, p. 131). Para o autor, o lugar é um subespaço, reflexo das contradições da sociedade capitalista, com suas diferenças no espaço que podem ser fontes de rentabilidade e investimentos ou o oposto, denominado como "produtividade geográfica".

Na obra intitulada Da totalidade ao lugar, Santos (2005) alerta para o risco de ideias pós-modernistas que sugerem a não existência do lugar. Segundo o autor, essas ideias banalizam, homogeneízam e esvaziam o lugar, utilizando metáforas que não servem para a análise da realidade. Posicionando-se contra essa corrente de pensamento, ele 
(2005, p. 158) afirma: "[m]uda o mundo e, ao mesmo tempo, mudam os lugares. Os eventos operam essa ligação entre os lugares e uma história em movimento. O lugar, aliás, define-se como funcionalização do mundo e é por ele [lugar] que o mundo é percebido empiricamente".

O lugar, na análise do autor (2005, p. 161), não se dissolve com a aceleração do tempo, mas se reafirma com a concretização das relações humanas, que são históricas: "[h]oje, mais importante que a consciência do lugar, é a consciência do mundo, obtida através do lugar".

Santos (1997), na análise do lugar em relação à globalização, que ele denomina como perversa, alerta para o que ele chama dea força dos lugares. Esse aspecto leva em conta as resistências que os lugares apresentam em seus cotidianos. Há movimentos da sociedade civil que podem ser ampliados em busca de outra globalização. O lugar, nesse sentido, não é passivo, mas ativo em propor uma globalização que valorize o ser humano. A esse respeito, o autor nos alerta para que consideremos o cotidiano na busca de novos sentidos para o lugar.

Damiani (2001) elaborou uma análise sobre o conceito de cotidiano relacionando-o ao lugar. Para a autora, o cotidiano é um nível de análise do espaço que centraliza a reprodução das relações sociais. Nele são mediados os níveis econômicos e políticos na esfera da realidade social, contudo, em sua contradição, resiste à vida privada e às vivências particulares dos indivíduos. Ainda, se relaciona ao lugar à medida que coloca questões complexas da totalidade-mundo nos lugares. "O lugar é a sociedade inteira, não só seus aspectos econômicos e políticos" (DAMIANI, 2001, p. 164). Para a autora, lugar e cotidiano se interpenetram, sendo o cotidiano o conjunto de atividades e relações que mediam a relação entre o lugar e o mundo.

Retomando a consideração de Santos (1997) de que a informação é hoje a principal base de divisão do trabalho, o cotidiano, como conceito que caminha subjacente ao lugar, ganha novas dimensões, inclusive espaciais. Esse cotidiano que se insere nos lugares torna-se relevante para a compreensão das relações sociais que se fazem na proximidade e que contribuem para a compreensão de mundo de que necessita o pensamento emancipador. "Com a modernização contemporânea, todos os lugares se mundializam" (SANTOS, 1997, p. 258).

Na linha crítica de análise, David Harvey (1998), em Condição pós-moderna, aborda de maneira indireta o conceito de lugar em sua discussão sobre as transformações do tempo e do espaço na modernidade e na pós-modernidade. Em uma abordagem histórica, Harvey (1998) faz uma análise do lugar trazendo importantes contribuições para pensarmos os lugares e suas modificações na história.

Na concepção de David Harvey (1998), existe uma dimensão geográfica da luta dos capitalistas pela manutenção do lucro, especialmente expressa pelo desenvolvimento do capitalismo. Novas necessidades de consumo e desejos são criadas na ânsia de manter o modo de produção baseado no lucro. A busca de novos mercados, matérias-primas e 
forças de trabalho lucrativas realocam a divisão do trabalho também espacialmente. A isso Harvey (1998, p. 103) nomeia como "movimento geográfico do capital e do trabalho", que resulta nas transformações dos lugares.

Em uma análise semelhante à de Harvey (1998), Silva (1978) afirma que o pensamento geográfico sempre descreveu e explicou o lugar e suas relações. Entretanto, somente agora há uma preocupação com a construção de um conhecimento geográfico que não seja fragmentado. O autor (1978, p. 127) afirma que o lugar era um dado isolado, "[...] uma parcela do espaço onde ocorria alguma coisa relacionada à população que o habitava ou que vinha de fora, de outros lugares".

Para Silva (1978), toda a problemática do objeto geográfico refere-se ao espaço, sendo o lugar, hierarquicamente falando, a categoria seguinte. Em sua concepção, o lugar manifesta-se como território, como região ou área, sendo eles expressões do lugar. "O espaço é, pois, o maior lugar possível" (SILVA, 1978, p. 7). Para ele, o espaço geográfico não pode ser considerado sem que contemple a população, e esta, por sua vez, percebe o espaço em que vive e desenvolve suas atividades nos lugares.

Ana Fani Alessandri Carlos (1996), em análise geográfica específica do lugar também na perspectiva crítica, afirma que nele se manifesta o que é global de forma contraditória, sendo este um ponto de articulação entre o local e o mundial. É, portanto, a realidade carregada de significado, uma parte da totalidade. Esse "próximo" (pensando a globalização na relação tempo-espaço) não é mais algo isolado do todo, mas uma representação, uma "amostra" desse todo, do mundo, da sociedade e de sua essência.

É no lugar que se concretizam as questões do mundo, de maneira contraditória e nada harmoniosa, próximas e distantes, onde os fenômenos se desmistificam. De outra maneira, como discute Santos (1997, p. 252), “[c]adalugar é, a sua maneira, o mundo", e sabemos que o mundo não é harmônico, mas conflituoso e profundamente desigual:

Cada lugar, porém, é ponto de encontro de lógicas que trabalham em diferentes escalas, reveladoras de níveis diversos, e às vezes, contrastantes, na busca da eficácia e do lucro [...] Assim se definem os lugares: como ponto de encontro de interesses longínquos e próximos, mundiais e locais, manifestados segundo uma gama de classificações que está se ampliando e mudando. (SANTOS, 1997, p. 18).

Reiteramos que o conceito de lugar ultrapassa a simples localização pura e despretensiosa e relaciona-se à própria articulação do espaço geográfico como revelador das contradições e desigualdades produzidas pelo sistema capitalista. Este, a cada dia, articula os lugares em decorrência da necessidade de ampliar o mundo da mercadoria (CARLOS, 2004).

Carlos (2004) afirma que o lugar se constitui tendencioso à homogeneização, contudo, preserva possibilidades de diferenciação, concordando com a força do lugar mencionada por Santos (1997). Assim, como o espaço é resultante de um processo de 
produção da vida, o lugar permite a compreensão desse espaço, pois revela, em seu cotidiano, os movimentos dessa produção social. Esse posicionamento nos leva a crer que, por suas especificidades, o lugar permite compreender as problemáticas do mundo por meio de sua espacialidade. "O mundo se descortina através do lugar" (CARLOS, 1996, p. 17).

O lugar revela, na espacialidade do cotidiano, do vivido, as relações sociais constituídas historicamente. A ideia de particular, identidade, reconhecimento e pertencimento, segundo Carlos (1996), são representativas de uma realidade global, inclusive no que concerne às desigualdades. A produção social que se dá em cada lugar não é autônoma e não se faz de forma alheia à determinação da divisão social do trabalho, atrelada à própria configuração do espaço geográfico. "O que se revela no lugar não é apenas a história de um povo, mas o peso da história da humanidade" (CARLOS, 1996, p. 23).

Ana Fani Alessandri Carlos (1996) admite aspectos do lugar que são captados pelo corpo, pelos sentidos, pelo uso do espaço - o espaço da vida, aspectos mais considerados na perspectiva humanística de Geografia. A apropriação do espaço por meio de sua vivência -seja pelo trabalho, pelo lazer ou por outro motivo -o torna lugar e esses significados do lugar lhe conferem características de humano. Entretanto, a autora não considera essas características subjetivas de maneira isolada, mas referenciadas a um contexto de mundo:

A produção espacial realiza-se no plano do cotidiano e aparece nas formas de apropriação, utilização e ocupação de um determinado lugar, num momento específico, e revela-se pelo uso como produto da divisão social e técnica do trabalho que produz uma morfologia espacial fragmentada e hierarquizada. Uma vez que cada sujeito se situa num espaço, o lugar permite pensar o viver, o habitar, o trabalho, o lazer enquanto situações vividas, revelando no nível do cotidiano, os conflitos do mundo moderno. (CARLOS, 1996, p. 26).

Em uma análise dialética, o lugar se coloca como unidade da vida social, fragmento que apreende o mundo. Desse ponto de vista, torna-se um conceito-chave ao se pensar sobre uma educação que pretenda questionar o mundo social, pois é nele que os seres humanos vivenciam, na prática, os conflitos.

O nível do cotidiano, das experiências e das situações vividas, citado por Carlos (1996), nos remete à Geografia humanística, ainda que não se detenha nela para explicar o lugar. Inspiradas pela fenomenologia, essas abordagens (Geografia humanística, cultural e comportamental) buscam uma análise dos fenômenos do conhecimento com base nas experiências concretas, intencionais e conscientes, de maneira holística. Essa perspectiva geográfica vê no lugar o espaço que é familiar, vivido, experienciado. Um dos principais conceitos na Geografia humanística, o lugar é o mundo da vida, da identidade e da cultura. 
Representativo dessa abordagem teórica, Yi-Fu Tuan (1983), em sua obra Espaço e lugar, elabora uma discussão sobre os conceitos que intitulam seu livro, sob a perspectiva humanística. Para Tuan (1983, p. 6), "o significado de espaço frequentemente se funde com o de lugar. O que começa com espaço indiferenciado transforma-se em lugar à medida que o conhecemos melhor e o dotamos de valor".

De acordo com esse autor, o espaço se "converte" em lugar quando é inteiramente familiarizado por nós, adquirindo definição e significado. Em sua elaboração, ele relaciona o conceito de lugar a sentimentos, emoções, refúgio e proteção -a ideia de permanência se liga à de lugar. São as pessoas que dão significado aos lugares, que se tornam o encontro da troca, da intimidade da casa, da cidade natal, etc. A ideia de familiarizar-se inteiramente com o lugar parece-nos carecer de certa relativização, tendo em vista que dificilmente determinado lugar pode ser completamente familiarizado.

Uma discussão interessante presente nas reflexões de Tuan (1983) diz respeito à ideia de que a arte é uma grande reveladora das experiências íntimas que se tem com os lugares. A literatura, a escultura, a arquitetura e a pintura expressam concepções de lugares que, de outro modo, talvez não fossem percebidas, pois se relacionam às experiências humanas com o lugar de maneira subjetiva. Podemos constatar essa ideia na música "Lugar", de Juraildes da Cruz (2002):

Quem diz seu lugar é seu povo

Quem diz o seu povo é o costume

Assim como o cheiro

é quem batiza o perfume

Um lugar não tem fronteira

Se no sangue corre a boa rima

Se tem versos de Caetano

Outros tantos manos com tarimba

Minas de Miltons e Laranjeiras

De Anhanguera vizinhança

No coração dividido Palmas

na esperança

Quando o eixo da Terra

Fizer a guinada certeira

O planalto central será

A Arca de Noé brasileira

Quem diz seu lugar... 
Disseram em Belém

Pra Maranhão temperado

Que o bom gosto é o Acre

Dos frutos Amazonados

Piauí filhos e netos

Em Fortaleza alegria

João Pessoa Pernan-frevo

Ancorando na Bahia

Mato Grosso não é mato só

Rio Grande águas salinas

Se tem praias em Maceió

Goiânia flor das meninas.

Quem diz seu lugar...

Rio de Janeiro no pé

Dessa mulata faceira

Capixaba acha e é

Uma semente brasileira

Lençolhando as cochilas

Vale Santa Curitibacana

De lá pra cá e embrenhei

Nas garoas paulistas

Rondônia e Roraima quem disse

Que o Norte e o Sul se unia

Num abraço de Oiapoque

Ao Chuí dos nossos dias.

A canção de Juraildes da Cruz (2002) caracteriza o lugar - o Brasil como um todo, enfatizando aspectos peculiares das diversas partes do País, entre regiões, estados e cidades. Dentre os aspectos mencionados pelo autor estão os naturais, culturais, humanos e históricos. Essa obra exemplifica a capacidade que as artes têm de expressar os lugares. No caso específico da música em questão, além dos aspectos humanísticos, referenciados por Tuan (1983), a composição traz uma dimensão dialética de lugar, por articular todo e parte e englobar, a uma temática, diversas dimensões do lugar. A poética está presente na canção, bem como os aspectos de regionalismo, identidade e reconhecimento, porém, para além do simplismo romântico, trazendo o olhar crítico para o lugar. 
As ideias de afetividade, identidade, emoção, sentimentos e vivências delineiam todo o texto da referida obra de Tuan (1983), por vezes podendo até parecer-nos "romantizada". Contudo, sua intenção é a de valorizar os aspectos humanos como componentes fundamentais da análise geográfica.

Para Tuan (1983), as pessoas não se prestam a detalhamentos que nada tem a ver com sua vida imediata, suas necessidades e singularidades. Ao contrário, elas se voltam a "dar cor" aos lugares à medida que eles se relacionam a seus afetos. Discordamos parcialmente do autor nesse sentido, pois a história mostra casos de mobilizações coletivas mundiais que surgem em catástrofes e em outros contextos, acionando pessoas de lugares longínquos e sem qualquer relação direta, imediata ou afetiva com o lugar.

Há trechos de discussão na obra de Tuan (1983, p. 21) que nos despertam interpretações para apontamentos críticos do lugar em suas relações dialéticas:

Quando residimos por muito tempo em determinado lugar, podemos conhecê-lo intimamente, porém, sua imagem pode não ser nítida, a menos que possamos também vê-lo de fora e pensemos em nossa experiência. A outro lugar pode faltar o peso da realidade porque o conhecemos apenas de fora.

O lugar pode não se configurar apenas pelo vivido, pelo experienciado, mas também pelas essências que a aparência comum do cotidiano trata de banalizar, levando a uma alienação da realidade que só o distanciamento pode revelar.

As análises humanísticas do lugar na Geografia nos interessam na busca de sentidos para o lugar, entretanto, objetivando a superação do imediatismo para a compreensão ampliada de mundo. Nesse sentido, é válido ressaltar a importância de não se ater ao fenômeno por meio de interpretações superficiais e subjetivas, que consideramos insuficientes para a emancipação humana, reduzindo as ações ao campo da individualidade e negando a dimensão de classe social.

$\mathrm{Na}$ prática cotidiana em sala de aula esses pares dialéticos ficam evidentes. A escola convive, como um lugar, ao mesmo tempo com realidades subjetivas e objetivas. As problemáticas advindas das particularidades dos alunos, de sua cultura, seus costumes, seus problemas pessoais e familiares (de saúde, segurança, condição econômica, estrutura familiar e social etc.) articulam-se aos conflitos de âmbito nacional e mundial: distribuição de renda, desigualdade, violência, corrupção, pobreza e tantos outros. A escola reflete as realidades objetivas da sociedade em seus aspectos materiais, positivos e/ou negativos, que derivam de questões econômicas, políticas e sociais. Por sua vez, elas estão relacionadas às questões locais nas quais a escola se insere.

O conceito de lugar na discussão geográfica científica encaminha-nos a estabelecer relações com a Geografia escolar. Como aponta Cavalcanti (2010b, p. 21), "pode-se dizer que ambas têm histórias paralelas, mas que se encontram, que se cruzam, 
que se interpenetram, que se influenciam mutuamente, guardando, assim, suas identidades e especificidades".

Buscando a interpenetração dialética entre Geografia científica e escolar, passamos ao tópico seguinte, em que nos dedicamos às considerações conceituais do lugar ao ensino escolar.

\section{O lugar na Geografia escolar}

A trajetória histórica da Geografia e sua constituição como disciplina escolar demonstram que o conhecimento geográfico de base científica e a Geografia ensinada nas escolas, organizada por currículos e determinados conteúdos, adquiriram características diferentes ao longo do tempo. "A Geografia escolar, portanto, é um conhecimento diferente da Geografia acadêmica. Ela é, pois, uma criação particular e original da escola, que responde a finalidades sociais que lhes são próprias" (CALLAI, 2013, p. 43).

As considerações do conceito de lugar para o ensino escolar, assim como na Geografia científica, tendem a se subscrever em categorias de análise que derivam de perspectivas críticas, humanísticas, culturais, comportamentais, neopositivistas, dentre outras. Os autores que tratam da temática, a nosso ver, em geral não abordam o conceito, restringindo-se exclusivamente a uma ou outra linha metodológica. Em muitos trabalhos, há o predomínio teórico da ideia de superação da Geografia tradicional, com um ensino que possibilite a formação cidadã e crítica e que avance em considerar a realidade do aluno no trabalho pedagógico com a Geografia em sala de aula. Isto é, o ensino crítico como o que se opõe ao tradicional, que prepare o sujeito para lidar com as complexidades do mundo.

Rafael Straforini (2008) posiciona-se por um ensino de Geografia, ao qual se refere como crítico, para além da oposição ao tradicional. Em seu trabalho, o autor reporta a necessidade de transformar o mundo, analisando o espaço geográfico como uma totalidade. Para que se chegue à compreensão da totalidade ou espaço é preciso utilizar, na prática educativa concreta, a fragmentação da totalidade para, depois, reconstruí-la por pontos de partida para o entendimento do espaço. Para isso, utiliza-se o que ele denomina como "conceitos-chaves da Geografia", que são paisagem, lugar, região e território.

Straforini (2008) considera as abordagens sintética e analítica -da parte para o todo ou vice-versa -como insuficientes para se estudar os lugares na realidade de um mundo globalizado. $\mathrm{O}$ autor insere o lugar em um contexto de globalização por compreender que, dadas as condições da atualidade, não é mais possível restringir o "lugar" do aluno ao imediato por si só, mas sim como ponto de partida para muitos lugares da totalidade, presentes na televisão, na internet e nas mídias em geral. $\mathrm{O}$ mundo globalizado não permite mais um ensino escolar que hierarquize o conhecimento, uma vez que na atualidade local e global ambos estão relacionados reciprocamente. 
O conceito de realidade imediata ou imediato concreto - o que na Geografia vamos chamar de lugar - utilizado na escola, não abrange sua dimensão atual. Com a globalização e o avanço técnico, científico e informacional, o lugar não pode ser entendido como uma categoria ou uma entidade que se encerra em si. (STRAFORINI, 2008, p. 92).

Para o autor, o que interessa, no ensino do lugar, não é se este partirá do próximo ou do distante, do bairro ou do mundo. Interessa as relações que serão construídas entre um e outro com vistas a compreender uma realidade que demanda transformação.

A menção de ensino transformador feita por Straforini (2008) nos interessa para pensar em um ensino de Geografia emancipador. Sua contribuição ao conceito de lugar em um ensino que prime por ser crítico se expressa também na sugestão da análise multiescalar dos lugares, a que ele chama de totalidade-mundo, superando as análises metodológicas analíticas e sintéticas. $\mathrm{Na}$ abordagem teórico-metodológica sintética, o estudo do lugar toma como ponto de partida o local mais próximo e vai avançando ao mais distante. $\mathrm{Na}$ analítica ocorre o contrário, iniciando-se os estudos pelo que é longe e desconhecido até chegar ao lugar de convívio (STRAFORINI, 2008). Na abordagem teórico-metodológica sintética, o estudo do lugar toma como ponto de partida o local mais próximo e vai avançando ao mais distante. Na analítica ocorre o contrário, iniciando-se os estudos pelo que é longe e desconhecido até chegar ao lugar de convívio (STRAFORINI, 2008).

Na perspectiva multiescalar não há uma hierarquização dos lugares, que se relacionam ao mesmo tempo, compartilhando a complexidade da realidade, desfragmentando os espaços. Straforini (2008) nos apresenta uma representação geográfica da análise multiescalar totalidade-mundo a qual adaptamos para nossa realidade, referenciando nosso próprio lugar (apresentada na Figura 1).

A escolha do bairro Jardim Guanabara III (representado na Figura 1) se justifica por se tratar do lugar em que se localiza a escola onde atuamos no ensino de Geografia no Ensino Fundamental. Compreendemos que os lugares não se explicam por eles mesmos, mas em uma relação complexa de reciprocidades, antagonismos e contradições, ou seja, dialética.

Na perspectiva multiescalar de análise, exemplificada por meio da Figura 1, os lugares compartilham seu todo e parte, independente de próximo ou distante. As escalas interagem em um mesmo nível de importância, demonstrando, de forma dialética, que os lugares não são hierarquizados, mas estabelecem uma relação contínua. 


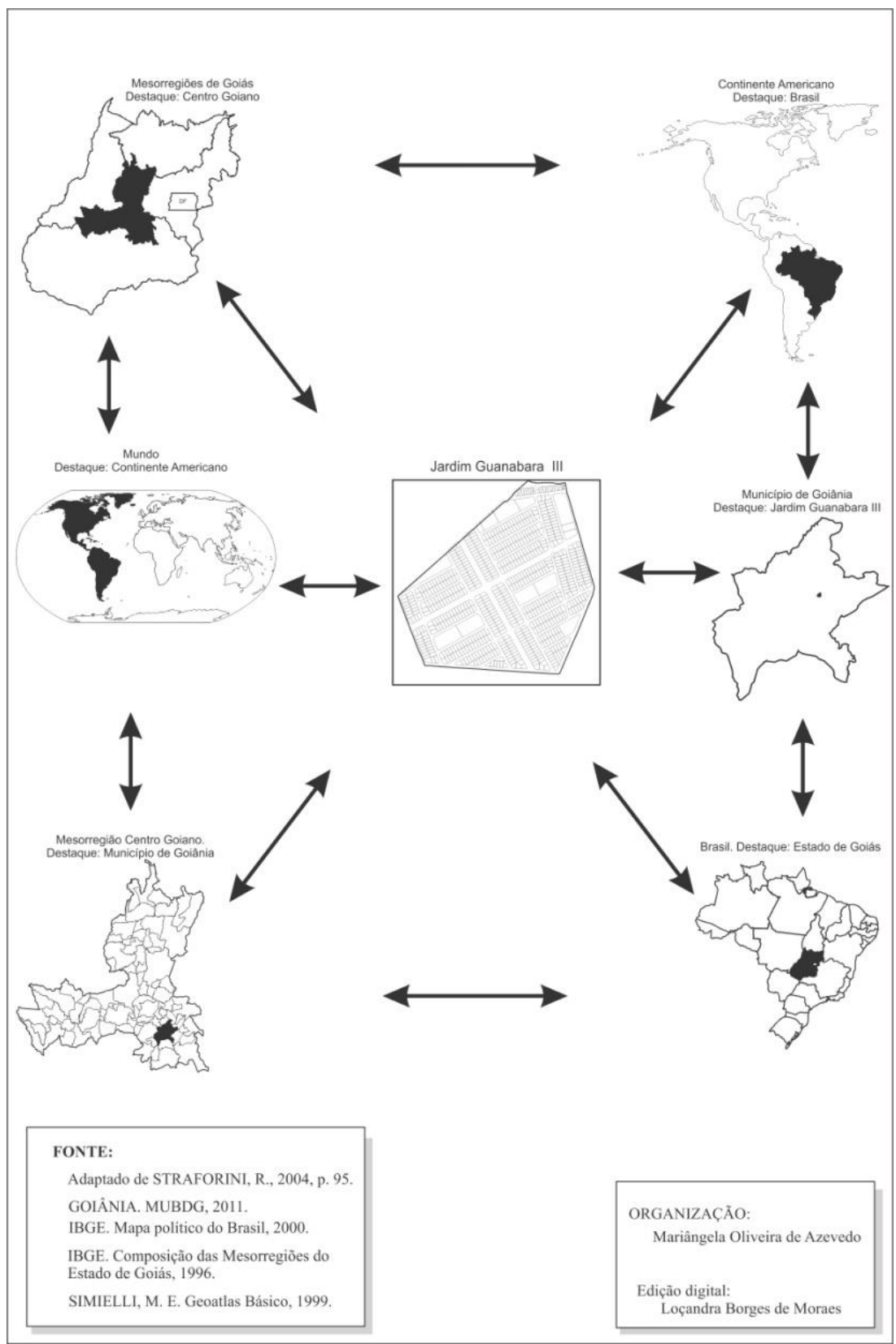

Figura 01: Totalidade-mundo 
Como Straforini (2008), Lana Cavalcanti (2005a, 2005b, 2009, 2010a, 2010b, 2013), nos diversos trabalhos em que têm se dedicado à discussão do ensino de Geografia na escola básica, considera o contexto da globalização imprescindível para pensar a espacialidade a ser apreendida pelos educandos. A autora enfatiza que, atualmente, as necessidades individuais e coletivas se reconfiguram a todo o momento. Portanto, o ensino de Geografia deve proporcionar ao aluno olhar, ao mesmo tempo, para o global e o local, atentando para seu lugar em um quadro geral, levando-o a formulações críticas (CAVALCANTI, 2010b).

Em Cavalcanti (2010b), a autora desenvolveu uma pesquisa com o intuito de analisar como se dá a formação de conhecimentos geográficos por alunos do Ensino Fundamental, a partir das representações sociais que eles possuíam dos principais conceitos geográficos (lugar, paisagem, natureza, sociedade, região e território). Em sua análise, constatou que o conceito de lugar, observado principalmente nos conteúdos que tratavam do bairro, aparecia, entre os alunos, relacionado a sentimentos afetivos como felicidade, amizade, liberdade, medo e outros. As relações pessoais pesam no momento de falar sobre seus espaços de convívio. Esse modo de ver o lugar condiz com a perspectiva humanística de Geografia, em que "o lugar é o espaço que se torna familiar ao indivíduo, é o espaço do vivido, experienciado" (CAVALCANTI, 2010b, p. 89).

Em outra discussão, Cavalcanti (2005a, p. 63), para pensar o conceito de lugar no ensino escolar, relaciona lugar e cidadania, especificando a cidade como "o lugar privilegiado do consumo". Segundo ela, o cidadão teria o direito, no modo de produção capitalista, de consumir os lugares, ou seja, usufruir deles, do que oferecem para o espaço de vivência. Contudo, nem sempre é isso que acontece.

A autora, baseando-se em Santos (2012), destaca, ainda, a diferenciação dos lugares no contexto das cidades - lugares proibidos, permitidos, públicos, privados etc. e sua relação com a segregação e a exclusão social/econômica. Lana Cavalcanti (2005a) avança, ainda, ao dizer que o conceito de cidadania aparece em muitos contextos da cidade, como equivalente ao de consumidor, sendo cidadão aquele que consome, e não quem não o faz.

Essas reflexões podem ser comumente observadas, na prática, em nosso cotidiano na cidade de Goiânia, em que há acepção social em relação a certos lugares da cidade. Shopping center's -espaços característicos de consumo e convivência no espaço urbano, específicos para determinado público, assim como restaurantes e lojas - e praças e parques da cidade - espaços que teoricamente são públicos para proveito de toda a população - notadamente reproduzem espaços privilegiados para um público em detrimento de outro. No caso da habitação, os condomínios fechados de alto padrão contrastam com bairros periféricos, às vezes bem próximos, revelando realidades antagônicas e contraditórias presentes na cidade. O lugar, nessa perspectiva, vai ao encontro da análise de Silva (2014, p. 101):

A cidade: a casa e a rua; o público e o privado; o centro de decisões políticas; o palco das realizações humanas; as luzes; o movimento; o paraíso do consumo. É na cidade que se encontra, no presente, a 
maior parte da população mundial e, nesse pulsar humano-urbano, consolida-se a tendência de tudo se tornar mercadoria.

A mercantilização dos lugares e a diferenciação espacial gerada por esse processo terminam por conferir, em espaços da cidade, lugares de desigualdade - destinados à moradia de pessoas com poder econômico - e outros reservados à população pobre. A cidadania, nesse contexto, conforme apontado por Cavalcanti (2005a), fica condicionada à classe que tem o poder de consumo.

Lana Cavalcanti (2005a, 2005b), nos trabalhos mencionados, aborda o conceito de lugar de modos distintos, mas que não se excluem ao pensar o ensino escolar. Tanto as questões afetivas quanto as sociais se relacionam aos lugares e devem ser consideradas no processo de ensino-aprendizagem, dadas as contextualizações necessárias (idade, contexto econômico, social, conteúdos, temáticas).

Sônia Castellar (2009), em sua abordagem do conteúdo cidade a partir do conceito de lugar, devido às especificidades de sua discussão, convencionou referir-se ao lugar como lugar de vivência. Para a autora, os lugares são caracterizados por singularidades que coexistem com aquilo que é comum e a compreensão dos lugares de vivência os torna significativo. Há de se considerar, nessa compreensão, a identidade dos indivíduos e seu meio (objetos naturais e fabricados).

As cidades são lugares de vivência nos quais as relações de produção se estabelecem, promovendo espaços fragmentados, dicotomizados e conflitivos. Ao mesmo tempo, o lugar manifesta sentidos de pertencimentos. Essa ambiguidade caracteriza os lugares de vivência, como a cidade, na coexistência das manifestações das raízes do local e/ou da globalização (CASTELLAR, 2009).

Ao se referir ao ensino escolar do conceito lugar (de vivência) por meio da cidade, Sônia Castellar (2009) aponta a preocupação em concretizar os conceitos, estabelecendo relações entre o formal e o informal, entre o saber escolarizado e o que o aluno traz de sua vivência, superando a superficialidade conceitual. A isso a autora intitula como método da análise da realidade vivida, para quem o ensino deve atentar para as mudanças históricas dos lugares, estimulando o olhar do aluno à comparação de espaços diferentes e escalas que levam ao local-global. "Estudar o lugar de vivência é vincular a ele questões que estão presentes em várias escalas de análise e permitir a associação criativa e referenciada na experiência concreta" (CASTELLAR, 2009, p. 49).

Nessa perspectiva, compreendemos que Castellar (2009), desde o momento em que convenciona nomear por "lugar de vivência", já imprime ao lugar características humanísticas, mas avançando ao conferir ao conceito uma postura dialética, por relacionálo ao mundo e à globalização.

Postura semelhante à de Castellar (2013) é a de Helena Competti Callai (2009a, 2009b, 2013). A autora se dedica a formulações da Geografia para a realidade escolar e, nos trabalhos mencionados, trata do conceito de lugar como possibilidade de aprendizado em Geografia: 
Estudar e compreender o lugar, em Geografia, significa entender o que acontece no espaço onde se vive para além das condições naturais ou humanas. Muitas vezes as explicações podem estar fora, sendo necessário buscar motivos tanto internos quanto externos para se compreender o que acontece em cada lugar. (CALLAI, 2009a, p. 84).

Para a autora, uma abordagem que se diga geográfica deve fundamentar-se em conceitos que encaminhem a compreensão de mundo e da sociedade em suas manifestações espaciais (CALLAI, 2009b).

Especificamente em O lugar e o ensino-aprendizagem em Geografia (2009b), ela discute o conceito de lugar na Geografia escolar e seu significado para a análise geográfica. Neste trabalho, considera que os avanços tecnológicos atuais, a aceleração produtiva, o consumo e outros fatores que acentuam a urbanização trazem como consequência os desgastes dos recursos naturais. Por sua vez, a aceleração das informações, somadas a esse contexto, faz com que o mundo assuma novas demandas e características. Para Callai, tudo isso age construindo os espaços singulares - os lugares , ao mesmo tempo em que eles se submetem ao que é global.

Helena Callai (2009b) discute, ainda, a formação do professor para atender a essas complexidades impostas pela modernidade no âmbito da formação por competências. Para ela, há de se considerar a dimensão técnica e pedagógica para o ensino que estabeleça relações complexas da espacialidade atual. Os interesses e as marcas da globalização se concretizam em lugares específicos, o que exige do professor a capacidade de atuar na complexidade contraditória do global-local.

Em seu trabalho A formação do profissional de Geografia, Callai (2013) aborda o conceito de lugar como possibilidade de aprendizado em Geografia, articulado ao conceito de cotidiano e à escola. Assim, lugar e cotidiano caminham juntos conceitualmente para a construção de conhecimentos geográficos. O lugar diz respeito à espacialidade e o cotidiano à vivência, às pessoas com que se convive, aos acontecimentos, aos aspectos culturais, que, ao final, constroem a identidade e o pertencimento (CALLAI, 2013).

Para a autora, o cotidiano permite a maior compreensão do lugar, pois daí é que o sujeito tem a capacidade de abstrair o entendimento por meio dos acontecimentos. Estes, por sua vez, não são aleatórios, "mágicos", e sim construídos historicamente e a Geografia pode auxiliar nessa compreensão. Callai (2013) considera que a interpretação do lugar não deve ser considerada somente nas diferenciações de escalas, mas também na articulação dos fatos, dos fenômenos e das forças, seja em âmbito real ou virtual. O desafio da Geografia é proporcionar a leitura do lugar para a compreensão do mundo.

Os trabalhos acerca do ensino de Geografia, que tratam do conceito de lugar, divergem em algumas questões específicas relacionadas à formação, aos objetivos e aos métodos, porém, são unânimes em destacar a importância do lugar para a aprendizagem em Geografia, para o conhecimento de mundo e da realidade do aluno. 


\section{Considerações finais}

Tanto a Geografia escolar quanto a acadêmica admitem o lugar como espaço da vida, da cultura, do conflito, do que é experienciado, provado, sentido, sofrido e comemorado no dia a dia. Essas reflexões, a nosso ver, podem contribuir para se ensinar a Geografia de maneira crítica, desvendando o que é ocultado nas espacialidades por meio dos lugares. A compreensão do lugar pode revelar como a desigualdade, advinda do modo de produção capitalista, articula-se aos espaços e em como isso interfere nas nossas vidas, como as relações sociais se materializam no espaço e se mostram por meio dos lugares.

Quase todos os autores referenciados neste artigo concordam quanto à superação do lugar como localidade, dimensão física espacial desconectada dos aspectos humanos, das contradições sociais e da relação multiescalar. Ademais, enfatizam a necessidade de considerar o lugar nas várias dimensões escalares, relacionando o global e o local dialeticamente em sua complexidade, em um contexto de globalização, opondo-se ao lugar segmentado.

A retomada teórica da produção a respeito do conceito de lugar na Geografia escolar nos leva a pensar que, ao elegermos esse conceito para ser tratado com os alunos em sala de aula, este não deve encerrar-se em si mesmo, mas como reflexo do que é o mundo, o todo, da universalidade para a particularidade e para singularidade e vice-versa. Como nos diz Santos (1997, p. 96), "[o] todo somente pode ser conhecido através do conhecimento das partes e as partes do conhecimento do todo".

$\mathrm{O}$ conceito de lugar permite-nos conhecer a mundialidade por meio das concretizações que se efetivam no local, levando em conta os aspectos hegemônicos e de resistências culturais. Os lugares configuram-se como espaços de exploração e de luta, de alienação e de emancipação. Cabe ao ensino o posicionamento metodológico de vislumbrar essas possibilidades do conceito lugar, por meio do ensino de Geografia, contribuindo ou não para a formação de seres humanos cientes do que ocorre no seu mundo, via espacialidade.

\section{Referências}

CALLAI, H. C. A formação do profissional de Geografia:o professor. Ijuí: Unijuí, 2013.

CALLAI, H. C. Estudar o lugar para compreender o mundo. In: CASTROGIOVANI, A. C.; CALLAI, H. C.; KAERCHER, N. A. (Org.). Ensino de Geografia: práticas e contextualizações no cotidiano. 7. ed. Porto Alegre: Mediação, 2009a.

CALLAI, H. C. O lugar e o ensino-aprendizagem da Geografia. In: GARRIDO, P. M. La espesura del lugar: reflexiones sobre el espacio en el mundo educativo. Santiago:

Universidad Academia de Humanismo Cristiano, 2009b.

CARLOS, A. F. A. O lugar no/do mundo. São Paulo: Hucitec, 1996. 
CARLOS, A. F. A. O espaço urbano: novos escritos sobre a cidade. São Paulo: Contexto, 2004.

CASTELLAR, S. M. V. Lugar de vivência: a cidade e a aprendizagem. In: GARRIDO, P. M. La espesura del lugar: reflexiones sobre el espacio en el mundo educativo. Santiago: Universidad Academia de Humanismo Cristiano, 2009.

CAVALCANTI, L. S. A educação geográfica e a formação de conceitos: a importância do lugar no ensino de Geografia. In: GARRIDO, P. M. La espesura del lugar: reflexiones sobre el espacio en el mundo educativo. Santiago: Universidad Academia de Humanismo Cristiano, 2009b.

CAVALCANTI, L. S. A. A Geografia escolar e a cidade: ensaios sobre o ensino de Geografia para a vida urbana cotidiana. 3. ed. Campinas: Papirus, 2010b.

CAVALCANTI, L. S. A. Cotidiano, mediação pedagógica e formação de conceitos: uma contribuição de Vygotsky ao ensino de Geografia. Caderno Cedes (UNICAMP), v. 25, n. 66, 2005b. Disponível em: http://www.scielo.br/pdf/ccedes/v25n66/a04v2566.pdf. Acesso em: 29 dez. 2015.

CAVALCANTI, L. S. A. Estudar o lugar para compreender o mundo. In:

CASTROGIOVANI, A. C.; CALLAI, H. C.; KAERCHER, N. A. (Org.). Ensino de Geografia: práticas e contextualizações no cotidiano. 7. ed. Porto Alegre: Mediação, 2009a.

CAVALCANTI, L. S. A. Geografia, escola e construção de conhecimentos. Campinas: Papirus, 2010a.

CAVALCANTI, L. S. A. Geografia e práticas de ensino. Goiânia: Alternativa, 2005a.

CAVALCANTI, L. S. A. Geografia escolar e a busca de abordagens teórico/práticas para realizar sua relevância social. In: SILVA, E. I.; PIRES, L. M. (Org.). Desafio da didática de Geografia. Goiânia: Ed. PUC-Goiás, 2013.

CRUZ, J. D. Lugar. Álbum: Hot dog latino. Anhanguera discos, 2002.

DAMIANI, A. L. O lugar e a produção do cotidiano. In: CARLOS, A. F. A. (Org.). Novos caminhos da Geografia. São Paulo: Contexto, 2001.

HARVEY, D. Condição pós-moderna. 7. ed. São Paulo: Loyola, 1998.

MOREIRA, R. O que é Geografia. São Paulo: Brasiliense, 1994.

SANTOS, D. O que é Geografia. Apostilado, 2007. Disponível em: http://www.ebah.com.br/content/ABAAAffIwAD/que-geografia-douglas-santos. Acesso em: 18 jan. 2016.

SANTOS, M. A natureza do espaço: técnica e tempo, razão e emoção. 2. ed. São Paulo: Hucitec, 1997. 
SANTOS, M. Da totalidade ao lugar. São Paulo: Edusp, 2005.

SANTOS, M. O espaço do cidadão. 7. ed. 1. reimpressão. São Paulo: Edusp, 2012.

SILVA, A. C. O espaço fora do lugar. São Paulo: Hucitec,1978.

SILVA, E. Ensino de cidade: lugar e cidadania. Estudos Geográficos, Rio Claro, p. 101114, jul./dez. 2014. Disponível em: http://www.periodicos.rc.biblioteca.unesp.br/index.php/estgeo. Acesso em: 18 jan. 2016.

STRAFORINI, R. Ensinar Geografia: o desafio da totalidade mundo nas séries iniciais. 2. ed. São Paulo: Annablume, 2008.

TUAN, Y. F. Espaço e lugar: a perspectiva da experiência. Tradução de Lívia de Oliveira. São Paulo: Difel, 1983.

\section{Mariângela Oliveira de Azevedo}

Mestra em Ensino na Educação Básica pelo Centro de Ensino e Pesquisa Aplicada à Educação (CEPAE), da Universidade Federal de Goiás (UFG), Licenciada em Pedagogia pela Faculdade de Educação da UFG. Atualmente, trabalha na Rede Municipal de Ensino de Goiânia, onde atua como professora da disciplina de Geografia no Ciclo II.

Rua 4, quadra Q, lote 9 - Vila Pedroso, Goiânia - GO. CEP: 74770-160.

E-mail: mariangela.azevedo@hotmail.com.

\section{Elson Rodrigues Olanda}

Doutor em Geografia pela Universidade Estadual Paulista, Campus de Presidente Prudente (2010); Mestre em Geografia, Especialista em Metodologia do Ensino Superior e Licenciado em Geografia pela Universidade Federal de Goiás-Regional Goiânia. Atualmente, é Professor Adjunto na Universidade Federal de Goiás, lotado no Centro de Ensino e Pesquisa Aplicada à Educação, onde ministra aulas no Ensino Fundamental, Médio e no Mestrado em Ensino na Educação Básica.

Rua Acapulco,Qd .181, 1t. 10 - Jardim Novo Mundo, Goiânia-GO, CEP 74710-180.

E-mail: elson.olanda@gmail.com. 